\title{
Assessing climate-change risks to cultural and natural resources in the Yakima River Basin, Washington, USA
}

\author{
James R. Hatten • Stephen M. Waste • Alec G. Maule
}

Received: 26 February 2014 / Accepted: 3 April 2014 / Published online: 29 April 2014

(C) The Author(s) (outside the USA) 2014. This article is published with open access at Springerlink.com

\begin{abstract}
We provide an overview of an interdisciplinary special issue that examines the influence of climate change on people and fish in the Yakima River Basin, USA. Jenni et al. (2013) addresses stakeholder-relevant climate change issues, such as water availability and uncertainty, with decision analysis tools. Montag et al. (2014) explores Yakama Tribal cultural values and well-being and their incorporation into the decision-making process. Graves and Maule (2012) simulates effects of climate change on stream temperatures under baseline conditions (1981-2005) and two future climate scenarios (increased air temperature of $1{ }^{\circ} \mathrm{C}$ and $2{ }^{\circ} \mathrm{C}$ ). Hardiman and Mesa (2013) looks at the effects of increased stream temperatures on juvenile steelhead growth with a bioenergetics model. Finally, Hatten et al. (2013) examines how changes in stream flow will affect salmonids with a rule-based fish habitat model. Our simulations indicate that future summer will be a very challenging season for salmonids when low flows and high water temperatures can restrict movement, inhibit or alter growth, and decrease habitat. While some of our simulations indicate salmonids may benefit from warmer water temperatures and increased winter flows, the majority of simulations produced less habitat. The floodplain and tributary habitats we sampled are representative of the larger landscape, so it is likely that climate change will reduce salmonid habitat potential throughout particular areas of the basin. Management strategies are needed to minimize potential salmonid habitat bottlenecks that may result from climate change, such as keeping streams cool through riparian protection, stream restoration, and the reduction of water diversions. An investment in decision analysis and support technologies can help managers understand tradeoffs under different climate scenarios and possibly improve water and fish conservation over the next century.
\end{abstract}

\section{Introduction}

River basins in the eastern portion of the Pacific Northwest USA (i.e., Oregon and Washington) are arid and characterized by low amounts of rainfall (e.g., $<15 \mathrm{~cm}$ ) in the lowlands, but high $($ e.g., $>250 \mathrm{~cm}$ ) precipitation in the form of snow in their western edges in

This article is part of a Special Topic on "Stakeholder Input to Climate Change Research in the Yakima River, Basin, WA" edited by Alec Maule and Stephen Waste.

J. R. Hatten $(\bowtie) \cdot$ S. M. Waste $\cdot$ A. G. Maule

U.S. Geological Survey, Western Fisheries Research Center, Columbia River Research Laboratory, Cook, WA 98605, USA

e-mail: jhatten@usgs.gov 
the Cascade Mountains. The Yakima River Basin (YRB) is located in eastern Washington State and typical of the region (Fig. 1). Aquatic resources of the YRB are used by many stakeholders including agriculturists, fishers and Native Americans - specifically the 14 tribes and bands that comprise the Yakama Nation. The livelihoods and well-being of those who rely on the water of the Yakima River might be affected by changes in the quality, quantity or timing of availability of that water under some climate change scenarios (Mantua and Francis 2004; Mastin 2008). The overriding objectives of the five articles in this special issue were (1) to give stakeholders the opportunity to share their thoughts on critical future climate change concerns with researchers; (2) to respond to concerns relating to anadromous salmonids by modeling effects on fish and their habitats; and (3) to provide the Yakama Nation-the members of which have inhabited the YRB for thousands of years and have tight socioeconomic bonds related to anadromous salmonids - an opportunity to conceptualize the possible effects of climate change on their tribal well-being.

Several fish populations in the YRB are among the 13 stocks of salmonids listed under the Endangered Species Act (ESA) and comprise a shared challenge for natural resource managers in the Columbia River Basin (CRB). The Biological Opinion for the Federal Columbia River Power System (FCRPS) and individual Recovery Plans are guided by the All-H approach (hydropower, habitat, harvest, and hatcheries) and implemented by the Action Agencies (Bonneville Power Administration, Army Corp of Engineers, and the US Bureau of Reclamation). Implementation activities under the Biological Opinion and the Recovery Plans rely heavily on habitat restoration and mitigation activities. Additionally, large scale

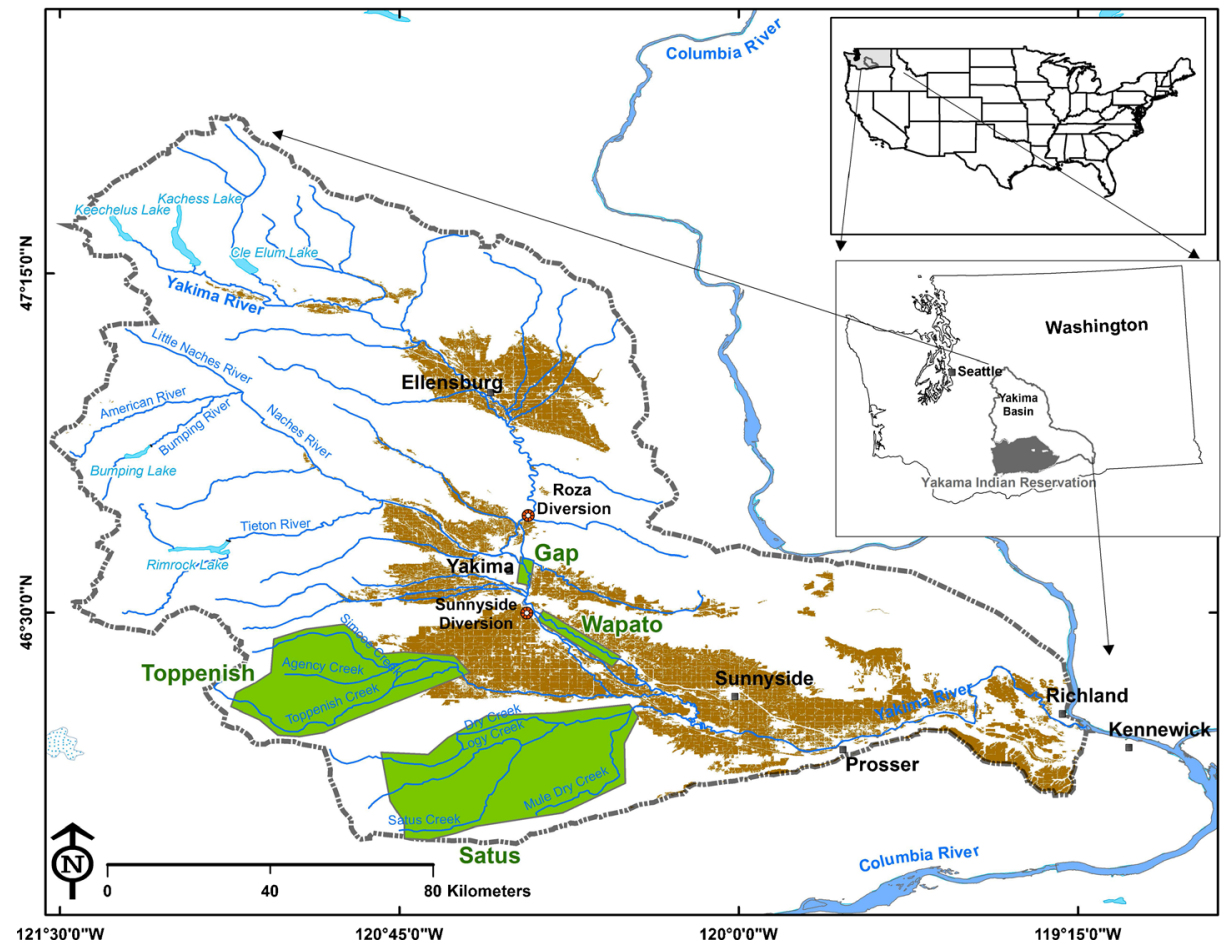

Fig. 1 A map of the Yakima River Basin (YRB), study locations (green), and agricultural areas (brown). The location of the YRB is displayed in the top inset while the Yakama Indian Reservation is shown in the second inset. Map credit: Thomas R. Batt 
restoration programs such as the Fish and Wildlife Program of the Northwest Power and Conservation Council and the Pacific Coastal Salmon Recovery Fund are supporting hundreds of habitat restoration and mitigation projects across the CRB. However, the FCRPS and ESA Recovery Plans address impacts resulting from, and with a clear nexus to, the operations of the FCRPS. They do not address "out of basin affects" or affects resulting from landscape scale stressors within the CRB, such as contaminants, invasive species, and climate change. Climate change has the potential to affect the amount and availability (timing) of water in the CRB with potential implications for agriculture, fisheries, and Tribal well-being that arise from a viable fishery.

In this introductory article we provide an overview and synthesis of five successive articles that focus on the development of methods and tools useful for evaluating potential climatechange effects on cultural and fisheries resources in the YRB. Jenni et al. (2013) identifies stakeholder-relevant climate change issues in the YRB (e.g., objectives, water uses and management options, climate change uncertainty) with decision analysis and presents a conceptual model. Montag et al. (2014) explores cultural values and components that influence tribal well-being and uses the conceptual model to illustrate how federal natural resource managers can incorporate intangible tribal cultural components into their decision-making. In response to stakeholder preferences (Montag et al., 2014), we focused our efforts on lower Yakima River tributaries, where endangered steelhead (Oncorhynchus mykiss) spawn and rear, and in key reaches of the main stem Yakima River, which contain critical habitat for coho (O. kisutch) and fall Chinook (O. tshawytscha) salmon. Thus, Graves and Maule (2012) simulates the effects of climate change on stream temperatures in two tributaries important for steelhead under baseline conditions (1981-2005) and two future climate scenarios (increased air temperature of $1{ }^{\circ} \mathrm{C}$ and $2{ }^{\circ} \mathrm{C}$ ), with the Stream Network Temperature Model. Hardiman and Mesa (2013) then looks at the effects of increased stream temperatures on juvenile steelhead growth in two tributary and one mainstem reach under baseline and future climate scenarios with a bioenergetics model. Finally, Hatten et al. (2013) examines how changes in stream flow will affect coho and fall Chinook salmon in two Yakima River mainstem reaches under baseline and future climate scenarios with a rule-based fish habitat model. Each article has been published as a standalone product since each tackled a unique climate change challenge, from decision-support tools to detailed habitat simulations under baseline and future conditions. This introduction integrates the findings in order to provide a broader, more holistic perspective on the challenges facing people, cultures, and wildlife resources in the YRB, with special emphasis on protecting USA Department of Interior trust resources.

\section{Methods and core findings}

\subsection{Decision analysis}

A conceptual model that highlights climate-related research useful to natural resource managers is described in Jenni et al. (2013; Fig. 2). Using decision analysis and conceptual diagrams (Clemen 1996), stakeholders identified key needs and objectives during a 4-day YRB workshop. The conceptual model highlights key areas of uncertainty that limit our understanding of climate change impacts and points to areas where additional study and engagement with stakeholders would be beneficial. The importance of different outcomes to stakeholders, including social and economic outcomes not typically investigated in climate impacts studies, was identified. Two embedded sub-models focus upon the total water supply 
and fisheries. Uncertainty in the water-supply sub-model produced by climate change includes snowpack, stream flow, reservoir storage and groundwater. Uncertainty in the fisheries submodel relates to out-of-basin conditions-such as ocean survival, migration, and hatchery fish affecting fish health, fish populations, and tribal fisheries. Importantly, managers identified that they can offset some of these uncertainties related to climate change with new or expanded reservoirs, groundwater and reservoir management, and fish habitat enhancements. An expanded fisheries sub-model (Jenni et al. 2013; Fig. 3) focuses on habitat requirements for anadromous salmonids. Factors such as water flow, depth, and temperature affect fish habitat, which in turn affects spawning, incubation, and rearing of the total fish population. Other factors such as genetic integrity, ocean survival, outmigration, and recruitment were also considered when assessing the health of the YRB fisheries and environment. Collectively, these factors all contribute to the total fish production, harvest allotment (i.e., sports, commercial and tribal fisheries), and social and cultural benefits available to the Yakama Nation.

\subsection{Tribal well-being}

The second article, Montag et al. (2014), explores Yakama Nation tribal well-being, identify cultural values and components that influence it, and shows how federal natural resource managers can incorporate tribal cultural components into its decision-making process. Several conceptual models are presented that focus on broad-scale tribal well-being (Montag et al., 2014; Fig. 1), first foods (Fig. 2), and community well-being (Fig. 3). Informed by the same decision analysis workshop as Jenni et al. (2013), stakeholders discussed how climate change may affect salmonid populations and identified potentially adverse impacts on Yakama Nation tribal well-being. Comprised of 14 tribes and bands, the Yakama Nation has inhabited the YRB for thousands of years, forming tight socio-economic bonds related to anadromous salmonids. Thus, any anthropogenic activities that affect the salmon population will have a direct and adverse effect on tribal well-being. Specifically, tribal well-being encompasses the functions, processes and elements that can sustain traditional tribal longevity and identity (Schuster 1975). The conceptual model uses the idea of social-ecological systems and the interactions between these systems. Six elements of Yakama Nation tribal well-being are (1) first foods, (2) family/individual well-being, (3) tribal community well-being, (4) ceremonies/ celebrations/arts, (5) traditional knowledge transmission, and (6) native language. Of these six elements, first foods, especially salmon, are the principal focus of Montag et al. (2014) with climate change and treaty rights highlighted. The authors stress that federal natural resource managers cannot successfully incorporate intangible tribal cultural components into their decision making process without first understanding important components of tribal well-being.

\subsection{Stream temperature}

The potential effects of climate change on stream temperatures in Satus and Toppenish watersheds, two important steelhead strongholds in the YRB, were assessed in the third article, Graves and Maule (2012). The models were constructed with the Stream Network Temperature Model (SNTEMP, Theurer et al. 1984; Bartholow 1989), calibrated in 2008 and tested in 2009. Next, the models were run for the baseline period (1981-2005) and two future climate scenarios with increased air temperature of $1{ }^{\circ} \mathrm{C}$ (Plus $1[\mathrm{P} 1]$ scenario) and $2{ }^{\circ} \mathrm{C}$ (Plus 2 [P2] scenario), simulating daily mean and maximum water temperatures over the 25-years period. Discharge data for the two streams were obtained with a watershed model designed for the YRB in a previous study (Mastin 2008). In each reach, discharge simulations 
decreased between April and September compared to the baseline, with the P2 scenario producing the largest decreases. Stream temperatures were inversely correlated to flow, with the P2 scenario producing the largest increase in stream temperatures compared to baseline, followed by the P1 scenario. Importantly, the two streams did not show the same sensitivity to changes in air temperature or stream flow, with Satus Creek water temperature rising at three times the rate as Toppenish Creek. Simulations showed Satus Creek is expected to exceed $22{ }^{\circ} \mathrm{C}$, a potential migration barrier to salmon and steelhead, two to three times as often compared to the baseline. In contrast, Toppenish Creek already exceeds the $22{ }^{\circ} \mathrm{C}$ barrier, so increases in water temperatures were predicted to have little effect on the availability of that system to salmonids. In addition, higher water temperatures can be detrimental to salmonid physiology, resulting in decreased growth rates and higher mortality. While Graves and Maule (2012) indicate that tributary streams in the YRB will react differently to increased air temperatures and reduced spring/summer stream flows, more streams will likely have increased migration barriers and produce negative physiological effects on salmonids in the YRB.

\subsection{Bioenergetics}

The effects of increased stream temperatures on juvenile steelhead growth in two tributaries of the Yakima River (Toppenish and Simcoe creeks; see Graves and Maule, 2012) and the Yakima River Gap reach were examined in a fourth article (Hardiman and Mesa, 2013). The authors obtained stream temperatures for the tributaries from Graves and Maule (2012) and mainstem temperature data from a support study (Voss and Maule, 2013). Under the same baseline and future climate scenarios as Graves and Maule (2012)), the authors used diet and fish-size data obtained from fieldwork and the Wisconsin bioenergetics model (Hanson et al. 1997) to estimate changes in growth of juvenile steelhead over 1- and 3-month periods. Data on diet for juvenile steelhead were provided by the Washington Department of Fish and Wildlife for June-September, 1998-2005. The five most common prey items, plus an "other" category, were supplied to the model, along with length and starting weights that were obtained from literature and field data. Growth rates for juvenile steelhead were simulated over a range of temperatures and at various feeding rates, with diet held constant. Bioenergetics modeling produced varied juvenile steelhead growth rates depending on age (0 or 1-2), stream reach, or date range (March-June; July-Oct). Simulated increases in daily mean stream temperatures $\left(1\right.$ and $\left.2{ }^{\circ} \mathrm{C}\right)$ increased juvenile steelhead growth in spring but reduced it in the summer and fall. Climate change may affect growth by modifying prey availability, prey quality, fish activity, seasonal stream temperatures, and local hydrology. Changes in management activities that alleviate stress on salmonids during the summer low-flow period, such as flow modification and/or riparian management, could result in increased juvenile steelhead growth and survival.

\subsection{Habitat simulations}

The potential effects of two climate change scenarios on the habitats of four life stages of coho salmon and three life stages of fall Chinook salmon in the Gap and Wapato reaches were evaluated in final article, Hatten et al. (2013). The habitat analysis focused on suitable hydraulic features (e.g., depth and velocity at a given discharge) and not water temperature since two-dimensional simulations of water temperature were not available. The watershed model (Mastin 2008) provided a discharge time series in each reach for baseline (1981-2005), P1, and P2 scenarios; a river-management model (Zagona et al. 2001) modified the discharge time series with Yakima River operational rules (USBR 2002); a 2D model (Steffler and Blackburn 2002) provided spatially explicit depth and velocity; while an expert panel provided 
salmonid habitat criteria using a Delphi consensus approach (Bovee et al. 2008; Zuboy 1981). Discharge-habitat functions were generated for each salmonid life stage (e.g., spawning, rearing) in main stem and side channels, and habitat time series for baseline, P1 and P2 scenarios. The spatial and temporal patterns in salmonid habitats differed by reach, life stage, and climate scenario. Seventy-five percent of the 28 discharge-habitat responses produced by the model exhibited a decrease in habitat quantity, with the P2 scenario producing the largest changes, followed by P1. Fry and spring/summer rearing habitats were the most sensitive to warming and flow modification for both species. Side channels generally produced more habitat than main stem and were more responsive to flow changes, demonstrating the importance of lateral connectivity in the floodplain. A discharge-habitat sensitivity analysis indicated that proactive management of regulated surface waters (i.e., increasing or decreasing flows) could lessen the impacts of climate change on salmonid habitats.

\section{Discussion}

Each of the five articles in this Special Issue examined a unique problem related to climate change in the YRB. Together they improve our understanding of the physical, biological and social interactions that may result from changes in climate and their implications for natural resource management in the Pacific Northwest. Topics we investigated included decision analysis and support, tribal well-being, stream temperatures, fish growth, and salmonid habitats. Collectively, our results indicate that summer will be especially challenging for salmonids in the YRB where low flows and high water temperatures may restrict movement, inhibit or alter growth, and decrease the availability of habitat. Some simulations, however, indicate that salmonids could benefit from warmer water temperatures and increased flows, depending on stream reach, season, and elevation. For example, Hardiman and Mesa (2013) found warmer water increased juvenile steelhead growth in springtime, while Hatten et al. (2013) projected that coho salmon spawning and over-wintering habitats increased in late fall and winter under climate change as simulated stream flows increased. However, our simulations did produce more negative than positive outcomes for salmonid habitat, leading us to conclude that there will likely be a decrease in salmonid habitat in portions of the YRB (i.e., mid to lower elevations). The magnitude of change will depend on the magnitude of climate change, but even a small decrease in habitat with an already depressed salmonid population can have impacts on ecosystem health and recreational opportunities (Jenni et al. 2013). These impacts might be felt keenly by Yakama Tribal members who rely on salmon for social, cultural, spiritual, subsistence and economic benefits (Montag et al. 2014).

Management strategies are needed to minimize potential salmonid habitat bottlenecks that may result from climate change, with an emphasis on keeping headwater streams and main stem rivers as cool and salmonid-friendly as possible, through riparian protection, stream restoration/enhancements, and the reduction of water diversions. Natural resource managers and stakeholders identified options at their disposal to alleviate some of the impacts of climate change (Jenni et al. 2013), such as new or expanded reservoirs, reservoir and groundwater management, and fish-habitat enhancements. Indeed, one of the paradoxes of climate change is that wild salmonids that reside outside of irrigation districts, such as in headwater streams, may face larger obstacles to survival than salmonids residing inside irrigation districts where managers can manipulate the irrigation system to benefit aquatic resources (Hatten et al. 2013).

In an effort to meet the water supply and ecosystem restoration needs in the YRB, the Bureau of Reclamation and Washington State Department of Ecology developed The Yakima River Basin Integrated Water Resource Management Plan Alternative (Integrated Plan), in 
cooperation with the Yakima River Basin Water Enhancement Project Workgroup (composed of representatives from tribal, Federal, State, county, and city governments, environmental organizations, and irrigation districts) (WDOE 2012). The Integrated Plan hopes to address a variety of water resource and ecosystem problems affecting fish passage and habitat, and agricultural, municipal, and domestic water supplies in the YRB. The Integrated Plan focuses on seven elements: reservoir fish passage, structural and operational changes to existing facilities, surface water storage, groundwater storage, habitat/watershed protection and enhancement, enhanced water conservation, and market reallocation. The Integrated Plan is expected to be beneficial to water supply for agriculture, municipal and domestic uses, and for resident and anadromous fish. Specifically, the Integrated Plan intends to improve main stem and tributary habitat, including habitat protection and enhancement, flow restoration, fish barrier removal, screening diversions, access to habitat above major reservoirs, and upstream and downstream passage. Considered to be one of the largest restoration projects attempted, it is a bold step by a diverse group of stakeholders to address the ESA challenges of today.

The Integrated Plan also provides an important foundation for developing and testing a basin-specific decision support system that can examine tradeoffs between different waterallocation schemes for people, fish and wildlife (see Bovee et al., 2008). Stream flows could be enhanced (e.g., increased, cooled) during critical periods by proper planning and forecasting and reservoir/irrigation manipulation. Significant gains in salmonid habitats could be achieved immediately if water managers chose to do so by reallocating flows in a more strategic fashion (Hatten et al. 2013, see Tables 2 and 3). The U.S. Bureau of Reclamation has a unique opportunity to play an important role in the management and conservation of numerous salmonid stocks across the 337 reservoirs, 476 dams, and 8,116 miles of irrigation canals in 17 western states over which they have management authority (http://www.usbr.gov/facts.html). A relatively small investment in decision analysis and support technologies (see Jenni et al. 2013) could complement existing management regimes by helping to clarify and quantify the tradeoffs possible under different climate scenarios, thus making possible significant improvements in water and fish conservation over the next century.

Acknowledgments We gratefully acknowledge the authors of each article for their dedication and persistence: Karen Jenni (Insight Decisions, LLC); David S. Graves (Columbia River Inter-Tribal Fish Commission); Jill M. Hardiman, Matthew G. Mesa, Thomas R. Batt, Patrick J. Connolly, Jessica M. Montag, Frank Voss, and Mark C. Mastin (U.S. Geological Survey); and Timothy L. Nieman (Decision Applications, Inc). Funding was provided by U.S. Geological Survey, Science Applications and Decision Support Program. Any use of trade, firm, or product names is for descriptive purposes only and does not imply endorsement of the U.S. Government.

Open Access This article is distributed under the terms of the Creative Commons Attribution License which permits any use, distribution, and reproduction in any medium, provided the original author(s) and the source are credited.

\section{References}

Bartholow JM (1989) Stream temperature investigations: field and analytic methods. Instream Flow Information Paper: No. 13. US Fish and Wildlife Service, Fort Collins, CO

Bovee KD, Waddle TJ, Talbert C, Hatten JR, Batt TR (2008) Development and application of a decision support system for water management investigations in the Upper Yakima River, Washington. U.S.Geological Survey Open-File Report 2008-1251, 289 p. Available online: http://pubs.usgs.gov/of/2008/1251/. Accessed 28 Jun 2012 
Clemen R (1996) Making hard decisions. Duxbury Press, Belmont

Graves D, Maule A (2012) Modeling water temperature in the Satus and Toppenish Watersheds of the Yakima River Basin in Washington, USA. Clim Chang. doi:10.1007/s10584-012-0643-X

Hanson PC, Johnson TB, Schindler DE, Kitchell JF (1997) Fish bioenergetics 3.0 for windows. Center for Limnology, University of Wisconsin-Madison and the University of Wisconsin Sea Grant Institute. WISCU-T-97-001

Hardiman JM, Mesa MG (2013) The effects of increased stream temperatures on juvenile steelhead growth in the Yakima River Basin based on projected climate change scenarios. Clim Chang. doi:10.1007/s10584-012-0627-x

Hatten JR, Batt TR, Connolly PJ, Maule AG (2013) Modeling effects of climate change on Yakima River salmonid habitats. Clim Chang. doi:10.1007/s10584-013-0980-4

Jenni K, Graves D, Hardiman J, Hatten J, Mastin M, Mesa M, Montag J, Nieman T, Voss F, Maule A (2013) Identifying stakeholder-relevant climate change impacts: a case study in the Yakima River Basin, Washington, USA. Clim Chang. doi:10.1007/s10584-013-0806-4

Mantua N, Francis RC (2004) Natural climate insurance for Pacific Northwest salmon and salmon fisheries: Finding our way through the entangled bank. Am Fish S S 43:121-134

Mastin MC (2008) Effects of potential future warming on runoff in the Yakima River Basin, Washington. USGS Scientific Investigations Report 2008-5124. Available on-line at: http://pubs.usgs.gov/sir/2008/5124/

Montag JM, Swan K, Nieman T, Hatten J, Mesa M, Graves D, Voss F, Mastin M, Hardiman J, Maule A (2014) Climate change and Yakama nation tribal well-being. Clim Chang. doi:10.1007/s10584-013-1001-3

Schuster HH (1975) Yakima Indian traditionalism: a study in continuity and change. Dissertation, University of Washington

Steffler P, Blackburn J (2002) Two-dimensional depth averaged model of river hydrodynamics and fish habitatIntroduction to depth averaged modeling and user's manual. University of Alberta, Edmonton, p 119, Available online: http://www.river2d.ualberta.ca/software/River2D.pdf. Accessed 28 Jun 2012

Theurer FD, Voos KA, Miller WJ (1984) Insteam water temperature model. Instream flow information paper: No. 16, US Fish and Wildlife Service

United States Bureau of Reclamation (USBR) (2002) Interim Comprehensive Basin Operating Plan for the Yakima Project, WA. Department of the Interior, United States Bureau of Reclamation, Yakima, 434 p. Available on-line at: http://www.usbr.gov/pn/programs/yrbwep/reports/operatingplan/index.html. Accessed 28 Jun 2012

Voss F, Maule AG (2013) Responding to stakeholder needs: a database-driven system for simulating water temperature in the lower Yakima River under climate change. U.S. Geological Survey Scientific Investigations Report 2013-1010, p 34

Washington Department of Ecology (WDOE) (2012) Yakima River Basin Integrated Water Resource Management Plan: Final Programmatic Environmental Impact Statement - Benton, Kittitas, Klickitat and Yakima Counties. Yakima, WA. Publication Number: 12-12-002. Available online: https://fortress.wa.gov/ ecy/publications/SummaryPages/1212002.html. Accessed 21 Mar 2014

Zagona EA, Fulp TJ, Shane R, Magee T, Foranflo HM (2001) Riverware: a generalized tool for complex reservoir system modeling. J Am Water Resour Assoc 37:913-929

Zuboy JR (1981) A new tool for fisheries managers: the Delphi technique: N. Am J Fish Manage 1:55-59 